nóesis Fragmentos de silentes bulliciosas Nancy Cárdenas y Violeta .../Volumen 29, Número 58-1 agosto - diciembre 2020 www.revistanoesis.mx 105

\title{
FRAGMENTOS DE SILENTES BULLICIOSAS NANCY CÁRDENAS Y VIOLETA BARRIENTOS
}

\author{
Fragments of silent bustling \\ Nancy Cardenas and Violeta Barrientos
}

Adriana Fuentes Ponce ${ }^{1}$

Fecha de recepción: 25 de septiembre de 2019.

Fecha de Aceptación: 11 de febrero de 2020. 


\section{Resumen}

El artículo tiene como objetivo presentar y problematizar algunos indicios de normatividades estrechamente ligadas a la división genérica, partiendo de un marco teórico feminista. Este texto muestra, desde un enfoque cualitativo, el cruce con la historia y la mitología griega y alude a una realidad contemporánea mediante el análisis comparativo de dos poemas latinoamericanos escritos en la década del noventa. Nancy Cárdenas, mexicana y Violeta Barrientos, peruana, exploran y construyen un sujeto lírico femenino que rompe con el modelo de feminidad y el amor canónico. La propuesta que se presenta contribuye a historiografiar la poesía lésbica escrita por mujeres en el siglo XX y ofrece elementos de análisis estilístico. Cárdenas alude a una escritora francesa cuya obra fue controvertida. Barrientos se remite a uno de los mitos emblemáticos de monstruosidad femenina. En sus versos dejan ver la relación erótico-afectiva entre mujeres y dan cuenta de las dificultades y resoluciones al incursionar en una forma de vida y prácticas sexuales que se alejan de lo aceptado socialmente. Entre los hallazgos se destaca la experiencia como un proceso en la conformación de la subjetividad, evidenciando la relación con el deseo y los vínculos amorosos, presentando así, sujetos femeninos que proponen y llevan a cabo acciones en vez de ser sujetos inertes o solo receptivos.

Palabras clave: Nancy Cárdenas, Violeta Barrientos, Lesbianismo, Poetas latinoamericanas Feminismo.

\section{Abstract}

In this article, some inkling of normativity linked to the gender division is problematized from a feminist theoretical framework. The qualitative approach crosses History and Greek mythology to recount a contemporary situation through a comparative analysis of two Latin American poems written in the 1990s. The Mexican poetess Nancy Cárdenas and The Peruvian poetess Violeta Barrientos explore and construct a feminine lyrical subject that breaks with the model of femininity and canonic love. The proposal presented contributes to the historiography of lesbian poetry written by women in the twentieth century and offers elements of stylistic analysis. Cárdenas refers to a French woman writer whose literary work was controversial. Barrientos refers to one of the emblematic myths of female monstrosity. Their verses reveal the erotic-affective relation between women and show the difficulties and resolutions to break into a way of life as well as having sexual practices that deviate from the socially accepted. The analysis indicates experience as a process in the formation of subjectivity because they show female subjects that propose and carry out actions instead of being inert or only receptive subjects.

Keywords: Nancy Cárdenas, Violeta Barrientos, Lesbianism, Latin American poets, Feminism. 


\section{Introducción}

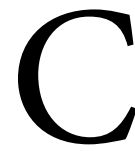

iertos poemas creados por la pluma de poetas latinoamericanas en las últimas dos décadas del siglo XX develan un sujeto lírico firme, sagaz, sapiente, que combina destreza y convic-

ción al mostrar en sus denuncias reflexiones y cuestionamientos sobre su propia experiencia y el contexto en el que se desenvuelve. Dichos versos plantean situaciones que expresan una relación lésbica que reformula sexualidad y cuerpo, así como el desmantelamiento de referentes sociales presentados a lo largo de la historia como inmutables. Y es precisamente esa ruptura al canon sobre la feminidad y una nueva manera de abordar la corporeidad como esta poesía visibiliza al sujeto lésbico que durante mucho tiempo había sido negado, enmascarado o disimulado.

En el texto que se presenta a continuación confluyen varios campos dentro de las humanidades: historia mitología y literatura. Cada una de ellas aporta matices y complejidades que favorecen cruzar las marcas que la biología y el tiempo cronológico nos han presentado, así pues, la lectura y planteamiento de ideas invitan a una reflexión desde otras aristas y al mismo tiempo trazan un hilo conductor cuyo interés es abrir espacios.

En parte de la producción poética de los ochenta y noventa del siglo pasado podemos reconocer la búsqueda de ese cambio enlazada a los planteamientos y demandas del movimiento feminista, así como del movimiento lésbico-homosexual; cabe decir que continúan vigentes en los albores del nuevo milenio. Este trabajo tiene como objetivo presentar algunos indicios de normatividades que están estrechamente ligadas a esa gran división en la que estamos inmersos los seres humanos: hombres y mujeres. No perdamos de vista que dicha división se ha afirmado como un saber que asume homogéneo a cada grupo; de ahí que (Muñiz, 2004) haya evidenciado la conformación de lo que denominó cultura de género. Por tanto, podremos observar esa cultura de género vinculada estrechamente al control ejercido a través de la sexualidad que imponen ciertos lineamientos mediante los cuales ha sido construido el cuerpo de las mujeres, sus manifestaciones erótico-amorosas y prácticas sexuales.

\section{1. $\mathrm{V}$ isibilizar a quienes visibilizaron ese otro sujeto lírico femenino}

Las relaciones erótico-amorosas entre mujeres se han catalogado de míticas, anormales o peligrosas, ya que la sexualidad ha estado presente en la construcción del sujeto y la organización de las sociedades, de ahí que sea gracias a la historia social y a las investigaciones realizadas en distintos ámbitos que conocemos experiencias y circunstancias vividas por mujeres cuyas acciones, tomas de decisión o respuestas a las problemáticas acontecidas transgredieron la heteronormatividad. En este sentido, Judith Walkowitz (1993) señala la prostitución, el aborto y las relaciones homosexuales, travestismo y amistades románticas, como algunos ejemplos en que fueron rechazadas, amonestadas porque sus comportamientos no fueron aceptados. Para la década del setenta, el lesbianismo en México seguía fuera del ámbito de la normalidad; al res- 
pecto, Ramón Valdiosera (1973) publica un estudio en que afirma que esas mujeres no debían ser incriminadas, pues era posible y necesario que hicieran algo para dejar de ser lesbianas.

Bajo esas premisas acontecidas, resulta imperante que, en las últimas décadas del siglo pasado, ante la perplejidad social, aquellos sujetos abyectos tuvieron rostro, y hablaron de su vivencia, personificando el parteaguas que a la fecha avanza por distintos caminos y ritmos. Este proceso de visibilización, como lo denomina Adriana Fuentes (2015), se advierte en el movimiento feminista y el movimiento lésbico homosexual, ambos vigentes y que iniciaron en la segunda mitad del siglo $\mathrm{XX}$. Las demandas, consignas, grupos y diversas actividades que han impactado en distintos sectores y políticas públicas son resultado de fortalecer lazos nacionales e internacionales a partir de reuniones, congresos, militancia y textos publicados. Los grupos conformados se han renovado continuamente y esto ha permitido reflexiones desde la militancia, la academia y entre ambas. Una característica importante es que las lesbianas feministas han impulsado la evidencia de las problemáticas por ser mujer y por ser lesbiana (Fuentes, 2015: 261-291). Conocer la cotidianidad de esas violencias a las que eran continuamente expuestas nos devela y permite comprender que usasen el recurso socialmente legitimado de estigmatizar al otro. Las posturas que defendían o bien denunciaban con la intención de explicar la construcción de los sujetos de género y sus implicaciones sociales se abrieron paso en la academia y en editoriales; de esta manera, los discursos al respecto lograron difundirse en mayor o menor grado. Es relevante recordar que quienes mostraron esa sombra constante y cotidiana dejaron un legado literario, el cual podríamos pensar que inició con Hall Radclyffe (1965) y su travesía para que fuese publicada su novela El pozo de la soledad, uno de los primeros textos que dejan ver una relación con connotación erótico-afectivasexual entre mujeres. A partir de esta obra, el contenido de la historia contada en las narraciones literarias ha presentado también otros desenlaces en cuanto la vida de los personajes y las formas de resolver las tensiones que implican una práctica sexual distinta a la legitimada.

La revisión de poemas publicados en este tema son una oportunidad de análisis para el siglo XXI, especialmente aquellos que fueron el medio para que escritoras latinoamericanas en las últimas décadas del siglo anterior conformaran un sujeto lírico que denunció las circunstancias presentadas en las que convergen complejidades, divergencias y desenlaces a partir de una sexualidad que no logró el consenso social para ser bien vista. En ciertos espacios, el lesbianismo permanece catalogado como desviación, aunque tal categoría haya sido erradicada de los manuales psiquiátricos a finales del siglo XX, por ello resulta imperante discutir y analizar sobre los aportes de aquellas producciones poéticas que no han sido exploradas desde los diferentes estudios de obras literarias. Cabe señalar que, afortunadamente, otras poetas se sumaron al periplo a lo largo de los siguientes años, y esto nos permite contrastar y conocer a ese sujeto lírico femenino que se aparta de alabanzas a la mesura y prudencia combinadas con una belleza enigmática que consolida los lineamientos establecidos desde una cultura de género imbricada en un imaginario social de figuras arquetípicas. Aclaro que:

La cultura de género crea y reproduce códigos de conducta basados en elaboraciones simbólicas promotoras de las representaciones hegemónicas de lo femenino y lo masculino, y es a partir de estos códigos y representaciones que se dirigen las 
acciones de los sujetos de género, desde su vida sexual hasta su participación política pasando por su intervención en la vida productiva, de tal manera que la cultura de género transita del llamado ámbito privado de la vida al público, sin que existan diferencias en las jerarquías de los papeles que cumplimos hombres y mujeres del mismo modo que se mantienen los referentes simbólicos, ya que no sólo se reproducen sino que se acoplan a las necesidades del poder (Muñiz: 2004: 32).

Los discursos que encontramos en los poemas a los que hago alusión, nos aclaran otros vértices, aristas novedosas, que invitan a un recorrido para reconocer formas de erotizar que pretendieron ser negadas, repudiadas o catalogadas efímeras, posicionándolas fuera de lo aceptado. Es así como las imágenes poéticas nos brindan intersticios que favorecen nuestro transitar en ese imaginario que se encuentra plasmado en la escritura y que ha fortalecido la producción literaria de mujeres latinoamericanas. Enfatizo que no pretendo con un poema revelar la riqueza de las contribuciones de estas poetas nacidas en México y Perú; no obstante, sí aspiro a que sea un acercamiento a las creaciones de Nancy Cárdenas y Violeta Barrientos, cuyas militancias en el feminismo y caminos andados en el ámbito literario que las acompañaron hasta lograr sus propias publicaciones encuentran puntos de convergencia y particularidades por explorar y discutir sobre la producción de cada una.

Los poemas a los que haré referencia en este texto no sólo rompen con el canon poético, también lo hacen con la feminidad, el amor plañidero, la obediencia ciega y la heterosexualidad como único camino para representar las prácticas sexuales humanas. Esta elección de poemas, publicados en la década del noventa, responde a que las temáticas planteadas me permitirán presentar posibilidades en las prácticas sexuales y relaciones erótico-afectivas en que la monogamia, la exclusividad y la decisión del sujeto lírico son exploradas desde diversos ámbitos, presentando una gama que reflexiona y manifiesta interlocuciones que deriva en relaciones que poco han sido nombradas o legitimadas. En ambos poemas encuentro el sello innegable del pensamiento feminista, ya que el sujeto lírico que construyen es un sujeto que se sabe mujer y que se erotiza a partir de otra mujer y se subjetiva de esa manera sin pensarse incompleta, invertida, peligrosa o enferma; en contraste, son evidentes las preocupaciones sobre el cuestionamiento a la heteronormatividad y los miedos a los que se enfrentan esos sujetos lésbicos a lo largo del proceso de visibilización.

Mi interés en este texto es apuntar a través de estas dos poetas la viabilidad de cavilar detenidamente sobre la noción de experiencia, puesto que mediante ella se tejen sucesos derivados del andamiaje que cada sujeto va construyendo y apropiándose. De esta manera vemos la injerencia de los aprendizajes, apropiaciones y reflexiones individuales y colectivas que denotan a ese sujeto múltiple apartado de la concepción de estatismo y homogeneidad. Los poemas seleccionados son pertinentes para exponer justamente a partir de teóricas como Teresa de Lauretis (1992) y Joan Scott (1999) el modo en que se ha problematizado la noción de experiencia, pues "en la medida en que recae directamente sobre los grandes temas que han surgido a raíz del movimiento femenino: la subjetividad, la sexualidad, el cuerpo y la actividad política feminista" (De Lauretis, 1992: 252) es que lo que sucede en el día a día deja de ser un asunto individual, íntimo y ajeno al 
contexto, y nos muestra cómo se interpelan. De ahí que los asuntos sucedidos puedan ser comprendidos no desde particularidades únicas y al mismo tiempo alejarse de la práctica de generalizar y sí develando cómo se conforma el entramado que constituyen los saberes y verdades en los que se construyen hombres y mujeres. Es importante mencionar que un aporte de Joan Scott con respecto a visibilizar la experiencia de quienes la historia social empezó a dar voz fueron precisamente homosexuales y mujeres, pues al insistir que "necesitamos considerar los procesos históricos que, a través del discurso, posicionan los sujetos y producen sus experiencias. No son los individuos los que tienen experiencia, son los sujetos los que se constituyen a través de la experiencia" (Scott, 1999: 86). Y estas afirmaciones sobre la experiencia abrieron la pauta para explicar que las posiciones de hombres y mujeres tenían que ser analizadas no como opuestas y sí desde la perspectiva de esa construcción genérica en la que esas subjetividades están íntimamente relacionadas con la organización social y la implicación política. En este sentido, encuentro en algunos poemas formas epigramáticas donde se plantea una situación o experiencia en la que las nociones de cuerpo y amor contradicen lo esperado desde la norma aceptada y al mismo tiempo denotan desenlaces en los que el sujeto lírico plantea una relación lésbica a través de la cual se renueva y reformula la feminidad y la sexualidad. De esta manera, gracias a estos poemas observaremos el erotismo amoroso entre mujeres posibilitando un desenlace que se aleja de lo monstruoso, lo anómalo o lo inadmisible como había sido presentado antes de estas propuestas.

\section{Una pluma femenina presenta la feminidad sexuada en la vejez}

La poesía de Nancy Cárdenas se inscribe en la poesía coloquial dado su estilo conversacional: el tono narrativo, testimonial da cuenta de lo ocurrido en la cotidianidad. Mediante frases de boleros, refranes y referentes conocidos contextualiza la intención de su propuesta. El lenguaje utilizado es fácilmente digerible. En el caso de Cárdenas pareciera un recurso recurrente en su militancia y resistencia feminista, tal vez, porque apelaba a ser inteligible y quien la leyese se identificara o reconociera a alguien en esas líneas. Por ejemplo, en el poema intitulado con el verso inicial Hoy (Cárdenas, 1994: 59) alude a un presente que puede ser pensado como juego con el tiempo, es decir, no tiene intención de especificar un día, todos pueden serlo. Por tanto, su vigencia está relacionada con el momento en que sea leído una y otra vez. También nos induce la idea de cambio y de posible movimiento que pese a expirar a las veinticuatro horas, el nuevo hoy arribará repetidamente. En los versos siguientes el sujeto lírico dialoga de manera irónica con el otro. Es posible pensar que sugiere a la sociedad expectante o cualquiera que esté fungiendo el papel de escucha:

más que nunca,

las mujeres podemos aspirar

a una ancianidad cálida y digna.

La ironía es enfática, pues en una frase constituida por tres palabras caben las siguientes preguntas: ¿Más que nunca porque ya no puede continuarse bajo ese régimen? ¿Más que nunca 
porque ya es posible debido a los cambios en el sistema? ¿Más que nunca porque es evidente la presencia de mujeres que han convenido en seguir otra manera de integrarse en la sociedad? Recordemos dos eventos cruciales en la década del setenta. El primero, cuando México fue sede de las conferencias del Año Internacional de la Mujer en el año 1975. Feministas mexicanas y de otros países abordaron las problemáticas de las mujeres. El tema del lesbianismo fue incluido, y si bien en ese momento todavía no había un grupo mexicano de lesbianas feministas, se presentó un manuscrito anónimo que denunciaba la situación de rechazo y persecución policiaca hacia la homosexualidad por parte de la sociedad mexicana. Tiempo después Claudia Hinojosa publicó que la redacción de tal documento fue autoría de Nancy Cárdenas. El segundo tuvo lugar dos años después: en 1977 Yan María Yoyólotl Castro, bajo el seudónimo de Jean Beltrán, participó en el Primer Simposio de la Mujer con su trabajo intitulado "Lesbianismo y Su Significado Social" (Fuentes, 2015:109-144).

Al estilo de los años ochenta en que el feminismo continuaba expandiéndose en nuestro país y generaba ámpulas en muchos sectores debido a que se contraponía a lineamientos y funciones que se enseñaban a las mujeres, se plantea así la evidente complejidad que viven las mujeres al llegar a una edad, que ha sido catalogada como poco productiva, de escasa o nula actividad, pues el imaginario social afianzado por la idea de que el cuerpo está en detrimento presenta esta etapa de la vida como un preámbulo a la muerte en el que los recuerdos y añoranzas desfilan día con día. Aquellos discursos feministas ${ }^{2}$ aseveraban de manera categórica que podría ocurrir lo que nunca se hubiere vislumbrado, ya que las acciones y respuestas a situaciones cotidianas antagonizaban los cánones establecidos, y para muestra basta un botón, continuando con los versos siguientes:

Ejercitar, divertir el cuerpo-alma

le dio buen resultado a la maestra Colette

Una de las grandes aportaciones del feminismo fue hablar del cuerpo y la sexualidad. Hasta ese momento la función principal asignada a las mujeres era la maternidad, es decir, que el instinto materno inherente a su género las situaba como cuidadoras y al mismo tiempo imposibilitadas para la toma de decisión sobre sí mismas. Gracias a los planteamientos de Simone de Beauvoir (1962) en el Segundo Sexo, el binomio cuerpo-mente empezó a ser desmantelado y en especial la relación de biología-naturaleza inherente a lo femenino y la cultura o razón vinculada a lo masculino. Las demandas feministas evidenciaban la violencia doméstica, el derecho a decidir sobre el aborto y la inclusión a una vida laboral y académica en la que las mujeres tuvieran las mismas oportunidades que los hombres. De ahí que una de las consignas feministas coreadas a nivel internacional fuera: no hay libertad política si no hay libertad sexual. Los versos citados visibilizan la sexualidad prohibida para las mujeres constituidas como sujetos de género.

2- Para ahondar temas referentes a la categoría de género, feminismo y cruces con otras categorías analíticas publicados en México se sugiere revisar los dos volúmenes de Conceptos clave en los estudios de género y Un fantasma recorre el siglo. 
Al evocar un personaje que forma parte de la historia de las mujeres que, incursionó públicamente como una mujer que no siguió con los lineamientos establecidos, Nancy Cárdenas sustenta la viabilidad de que ocurra tal circunstancia y, al mismo tiempo, homenajea su experiencia. Y he aquí la vuelta de tuerca cuando inserta ese estilo de vida que fuese incómodo y ambiguo para quienes la conocieron y convivieron con ella, y qué irrefutable es, como veremos posteriormente, que fue un parteaguas en la historia de las mujeres y para las representaciones del cuerpo y la sexualidad. Precisamente, Joan Scott afirma "La experiencia es una historia del sujeto. El lenguaje es el espacio de la representación de la historia. En consecuencia, la explicación histórica no puede separar ambas cosas" (Scott, 1999: 107). La principal intención al aludir a la noción de experiencia desde la teoría feminista fue desmarcarla de una connotación de individualidad exclusiva, evidenciando su implicación en el proceso que conforma la subjetividad. Mostrar la experiencia como un engrane que ayuda a problematizar esos sucesos que no son exclusivos, y sí, a veces, excluyentes. Con esto quiero decir que cuando esas denominaciones se perfilan hacia una taxonomía sostenida mediante argumentaciones que confirman generalizaciones a partir de la división genérica, o bien, una patologización de acuerdo con ciertos comportamientos catalogados anómalos, se transforman en verdades absolutas incuestionables. He ahí la estrategia feminista al retomar la experiencia: hacer visible lo existente, socializarla entre quienes la comparten y no como anécdotas personales inconexas. Por lo tanto, incorporar la noción de experiencia al lenguaje científico y tornarla en categoría de análisis al interpretar y complejizar acontecimientos en las vidas de las mujeres, devela cómo ha sido conformada la normalización del entramado cuerpo, género y sexualidad (entre otros más). Teorizar al respecto es buscar otros marcos explicativos para entender cómo han sido construidos esos entramados y generar propuestas desde nuevas perspectivas.

Las mujeres escritoras poco a poco descubrieron e implementaron condiciones para dar cauce a sus intereses pese a las adversidades que tuviesen que sortear. Fueron distintos momentos a lo largo de la historia en que las mujeres optaron por ocultar sus nombres, permanecieron en el anonimato debido a que usaban seudónimos para impedir que fuesen reconocidas y por ello merecedoras a una sentencia de diversa índole. Durante varias décadas las mujeres no eran consideradas sujetos viables para el aprendizaje intelectual y mucho menos para la creación literaria. Ante este panorama, Mary Ann Evans llevó a la fama el nombre de George Eliot; Armandine Dupin se hizo nombrar George Sand; las hermanas Brontë: Emily, Charlotte y Anne se llamaron a sí mismas Currer, Ellis y Acton Bell respectivamente. Una emblemática escritora francesa rompió con esta práctica, si bien sus primeras obras las firmó su esposo, posteriormente lo hizo ella misma. Larga fue su vida, 91 años atestiguaron la trascendencia de su proceder. Su producción literaria ha sido estudiada por expertos y homenajeada por la crítica, además, traducida en varios idiomas. En 1945 se convirtió en la primera mujer elegida para formar parte de la Académie Goncourt. Es preciso destacar que cientos de personas estuvieron en los funerales nacionales de Sidonie-Gabrielle Colette en agosto de 1954 (Thurman, 2006).

La elección de Nancy Cárdenas de apuntar a esta talentosa escritora, actriz de music hall, definida por algunos como la primera mujer moderna del siglo XX que marcó un antes y un después, nos evidencia un recorrido que transgrede lo establecido, una mujer que se muestra y 
explicita la sexualidad y erotismo como uno de los temas abordados en sus novelas; al conocer su biografía, podría pensarse que pudiesen referir anécdotas de su propia vida. Justamente su estilo, nada común y alejado de normas establecidas, provocó controversias. Colette fue una escritora y actriz en el ámbito teatral, su fascinante vida inició en la época del decadentismo de finales del siglo XIX y llegó a su fin en los años cincuenta del siguiente siglo en la ciudad de París. El erotismo que mostró en sus obras refleja personajes líricos femeninos que no se dejan llevar por lo establecido, por tanto, su construcción dista de las características de sumisión y preocupación de salvaguardar las funciones imputadas a las mujeres. Es por ello por lo que cuando el sujeto lírico en el poema de Nancy Cárdenas nombra a la maestra Colette, nos evoca a un sujeto cuya obra literaria tuvo un papel importante en la literatura, convirtiéndose también en ícono de muchas feministas. En palabras de Maricarmen García “...Colette...logra, primero a través del arte y después personalmente, traspasar los límites de esa tradición en busca de su propia autonomía y realización" (García, 2003: 72). Evidentemente su obra es un referente para abordar las relaciones erótico-amorosas entre mujeres, para nombrar las relaciones intergeneracionales y visibilizar subjetividades liminales que son propicias para elaborar la experiencia y observar otra forma de vida.

En el siglo XX podemos observar que las mujeres en diferentes momentos y contextos de sociedades heteronormadas permanecen como eternas infantes, casi asexuadas o siendo regulado cómo, cuándo y con quién realizarán las prácticas sexuales admitidas, es decir, se encuentran bajo supervisión y aprobación de sus actos por parte de los miembros que conforman su entorno familiar, por tanto, el cuidado y protección en la vejez proviene del seno familiar. De acuerdo con Sara Arber y Ginn Jay hay una relación entre género y envejecimiento y ésta se refleja en las problemáticas específicas en hombres y mujeres en cuanto a sexualidad, independencia, toma de decisiones, cambios en el estado de ánimo, así como manifestaciones de tristeza o enojo (Arber y Jay, 1996), pues las funciones destinadas a lo largo de la vida a partir de una cultura de género, que delimita y prescribe un comportamiento esperado para el ocaso de la vida y conlleva a esa especificación genérica. Según el estudio gerontológico de Delia Sánchez se distinguen problemas de interacción al interior de las parejas, lo que nos lleva a reflexionar que no es necesariamente el cansancio, la rutina compartida entre los cónyuges, sino que responde a la manera en que han llevado su cotidianidad al estar cimentados en esos saberes consensuados sobre los comportamientos aceptados y promovidos para la senectud (Sánchez, 2000).

En estos versos Nancy Cárdenas plantea que la sexualidad es un aspecto político y cotidiano mediante el cual se regula la conducta de las mujeres incluyendo la vejez, pues en esa etapa de su vida lo normalmente aceptado es que sean abuelas, viudas o acompañantes del esposo, y difícilmente será permitido que realicen prácticas sexuales o inicien una relación erótico-afectiva. Parafraseando a Judith Butler en Cuerpos que importan, es de llamar la atención que siga vigente preguntarse por qué hay cuerpos que importan y otros que no, "la paradoja de la sujeción es precisamente que el sujeto que habría de oponerse a tales normas ha sido habilitado, si no ya producido, por esas mismas normas." (Butler, 2002: 38). Resulta interesante encontrar algún intersticio en que pese a esta contradicción en que la subjetividad es construida, se exponga como evidencia la experiencia de alguien como Colette, que precisamente por haber incursionado en 
una serie de prácticas sexuales con hombres y mujeres, haya perfilado sus últimos días dando continuidad al deseo que podría sentir sin contemplar que la edad pudiera ser un impedimento para ello. Veamos la relevancia que cobra la reflexión que el sujeto lírico enuncia en los tres versos con los que concluye el poema:

(Mi vejez

podría haber sido

una suave manera de preparar la tuya, digo).

Estos versos aparecen insertos en un paréntesis que sirve para dar una idea de nota final o de un corolario. En los seis versos previos el sujeto lírico ha manifestado como viable la posibilidad en que vislumbra la vejez de las mujeres alejándose de las funciones, actitudes y acciones esperadas. En este sentido, su propuesta de "ancianidad cálida y digna" es el quiebre que plantea: atender y escuchar el deseo. Este sujeto lírico invita a sumergirse en la diversión producto del "cuerpo-alma”. El adjetivo posesivo en primera persona del singular califica el sustantivo vejez, de ahí que podamos interpretar que ese sujeto lírico se encuentra en dicha etapa de la vida, o hace referencia pensándose en ella. Así pues, la idea sintáctica es decir, la elección de las palabras con las que Cárdenas ha construido estos versos, presenta a una mujer que se posiciona desde su vejez y que coquetea con una mujer más joven que ella. Al parecer hay, quizá, una negativa o un término en esa relación, pues Cárdenas cierra el poema con los versos: "podría haber sido/una suave manera de preparar la tuya, digo". Estos versos nos develan que no obtuvo el resultado esperado. Sin embargo, ese sujeto lírico protagónico sigue su propio camino inspirada en la experiencia conocida de la maestra Colette. El sujeto lírico se despide de su interlocutora haciéndole ver que, de haberse sumado, esa vejez que vivirá en algún momento habría sido más suave.

El sujeto lírico no se detiene, la palabra final es: "digo"; apela al uso coloquial, ya que, digo es una manera de expresar opinión, sostener los argumentos, pese a que quien escuche esté o no de acuerdo. En el poema Cárdenas, denota certeza de lo que piensa y asume el sujeto lírico para su vejez, para la vejez de las mujeres. De ahí que mi interpretación sea un mensaje de buscar la oportunidad para una vejez no inerte, de obediencia de los lineamientos establecidos, sino de un hacer valer los años para recorrer y explorar su deseo. Me parece que la mayor relevancia de este poema es dar continuidad al propio pensamiento y decisión, así como también entender la negativa de aquella y, no por ello, detenerse y optar por hacer ese último llamado a pensar sobre la vejez y el camino para propiciar que sea replanteada. Cierto es que los periodos de infancia y vejez han sido vislumbrados como momentos asexuados en la vida de los sujetos. Gran parte esta idea se encuentra relacionada con que hombres y mujeres buscan pareja en cierto momento de la vida para complementarse y cumplir con las funciones esperadas como la procreación. Otra más es que hay etapas vinculadas con la edad, sin tomar en cuenta circunstancias, contextos, necesidades y elecciones personales. Específicamente, pensar en la vejez de las mujeres nos remite a que los comportamientos que pueden o no ser aceptados son resultado de una carga moral que las clasificará como sujetos normales o inadecuados.

Observamos en este sujeto lírico, situado en plena ebullición feminista en México, una similitud con una militante lésbica feminista de nombre Luz María Medina por darse a la tarea de construir un lugar de retiro para cuando llegasen al ocaso de su vida aquellas mujeres que hubiesen transgredido las normas 
heteronormativas y hubiesen optado por no decantarse por un hombre para vivir en pareja. El proyecto consolidado lo integran veintidós mujeres en las Vigas, Veracruz, ${ }^{3}$ pues se dieron cuenta de que "más que nunca" (Cárdenas, 1994: 59) era (y sigue siendo) necesario prever una vejez en la que puedan continuar gozando de una sexualidad plena en un espacio en el que prolonguen una vida independiente y no sometidas de nueva cuenta a una heterosexualidad obligatoria de la que se apartaron hace varias décadas.

\section{Develando al sujeto lírico lésbico. Quitando la máscara del repudio}

El poema La cabeza de Medusa, escrito por Violeta Barrientos en 1992 e impreso por segunda ocasión en el año 2013, es relevante en este texto por la manera en que interpela con las características que circunscribieron a aquella mortal en el canon que vislumbra la dualidad fluctuante entre el bien y el mal, la aceptación y el rechazo, el enigma detrás de la pureza y la transgresión imputados de manera inexorable a esos personajes denominados femeninos, y que, de acuerdo con situaciones acaecidas y desenlace de los mismos, se tornaron protagonistas de beneficios o escarnios ejemplares.

El título nos remonta a un personaje temible y emblemático de monstruosidad y repudio que convertía a los hombres en piedra. Aludo a un conocimiento popular para decir que la referencia a esa mirada evoca intensa maldad y frialdad de la que fueron víctimas un sinfín de hombres, y que tales muertes concluyeron gracias a la pericia y destreza de un valiente que asestó su espada arrancando la cabeza con cabellera ofidia. También podemos observarlo en las réplicas de las numerosas formas de representaciones que se han realizado sobre tal acontecimiento. La imagen esculpida y esbozada en distintos momentos a lo largo de la historia de la humanidad y en casi todas estas recreaciones, exhiben la cabeza de aquella como trofeo y promesa cumplida de Perseo al rey Polidectes. Recordemos que la Gorgona Medusa ${ }^{4}$ fue además un insigne talismán en el mundo clásico grecorromano, usado como protección de enemigos a quien lo portase, motivo por el cual encontramos esta cabeza en escudos y armaduras de guerreros. Ante los ojos de Atenea, el comportamiento de esa mortal en uno de sus templos con Poseidón fue reprobable $y$, por consecuencia, merecedora de una condena que le recordase su repudio; no obstante, es peculiar y significativo que una vez escindida la cabeza y tras varias aventuras y batallas en las que fue utilizada, la diosa Atenea la recogiese y fijara perennemente en su égida.

El poema La cabeza de Medusa (Barrientos, 2013) nos remite por vez primera a la diosa Atenea y no al héroe que fuera acreedor de vítores procedentes de blandir su larga y reluciente arma sobre el cuello de Medusa. La elección del sujeto femenino que da nombre al poema nos presenta a Medusa después de haber sido cercenada de movimiento y que transmutó a objeto-propiedad en el amuleto protector de quien lo poseyera:

Y aquí está tu cabeza,

pendiente de mi sueño,

3- Para conocer más sobre Fortaleza de la Luna revisar el libro Decidir sobre el propio cuerpo.

4- Algunos trabajos sobre el mito de la Medusa y cuyas aportaciones resultan esclarecedoras son de la autoría de Mercedes Aguirre (1998) y Ana María Vázquez (2013). 
luminosa en la penumbra

La idea sintáctica, que anuncia dos vías al enfatizar las características silentes, vigía y avizora, puede pensarse en ámbitos imaginario u onírico, o bien, situada en el lugar sagrado de Atenea. En ambos casos nos revela a dos sujetos líricos femeninos que participan en el juego de la seducción, el placer y la imposibilidad de continuar y paralizarse ante ello.

Si bien el pelo ha sido una de las metonimias más socorridas en la poesía canónica para privilegiar lo femenino, el uso de adjetivaciones respecto a la sedosidad, al largo y abundancia, para develar su semblante, cubrirlo cual delgada cortina o como medio que enfatiza gestos y expresión. En el caso de $L a$ cabeza de Medusa, cabe acotar que tiene un antes y un después al castigo infligido por la diosa Atenea. Previo al agravio suscitado por profanar el templo y haberse llevado la consumación de la violación o seducción de Poseidón, según distintas versiones, esta mortal (Aguirre, 1998: 2) era una joven agraciada con una belleza excepcional, a quien se le atribuía su andar, rostro y cabellera como signo de sensualidad y voluptuosidad. Vemos que hay una evocación al actuar seguro y sabedor de sus encantos, a un movimiento certero y firme en los versos siguientes:

Tu melena se agita extendiendo sus tentáculos,

múltiples brazos, cabezas

de serpiente hurgando en mis orificios

El aspecto ofidio deja de ser temible ahora provoca fascinación en quien la está mirando; es pertinente recordar que lo que encolerizó a la diosa fue que, a pesar de la transformación del rostro y cabellera, Medusa continuaba con ese andar seductor. Aquí la vuelta de tuerca en estos versos que enseñan a una Atenea, a un sujeto femenino, receptor de sí misma, por tanto atenta a sus deseos, así como también a la incitante Cabeza de Medusa que proporciona placer al sujeto lírico femenino con quien tiene un encuentro erótico. Que esta melena tenga movimiento y busque el placer conocido, le otorga de nuevo la posibilidad de llevar a cabo prácticas sexuales elegidas por ella.

Este poema deconstruye el mito de la Medusa y, como resultado, obliga a cambiar el esquema ideológico con el que ha sido vista y transmitida la historia de ese personaje femenino a quien hemos aprendido a temer, sentir repugnancia y aceptar sin objeción alguna que su esencia está homologada a la monstruosidad, no sólo por su apariencia o por la materialidad con la que está compuesta, sino porque además hay una imposibilidad para verla, pues existe una idea preconcebida que impide explorarla con detenimiento. Los relatos difundidos que evocan la escultura de la Medusa, o alguna representación de ella, han hecho un trabajo performativo que la ha ataviado y conformado como una abyección que ha sido derribada por la representación hegemónica que la aniquila separando la cabeza del cuerpo.

Este personaje mítico femenino atentó contra lo establecido, esto nos permite observar cómo "el género es performativo [...] pues posee una determinada expresión y manifestación; ya que la apariencia del género está condicionada por normas obligatorias que lo hacen definirse en un sentido u otro" (Butler, 2009: 322). La historia contada y replicada se apega ineludiblemente a una serie de normas legitimadas de lo que se espera de hombres y mujeres o bien de la pena que se harán acreedores quienes no se apeguen a ello. En contraste a esto, Violeta Barrientos, a través de la misma performatividad nos conduce, 
en otro sentido y nos destapa lo que ha sido silenciado u oculto. Los siguientes versos visibilizan precisamente cómo sucede en Medusa este proceso en que puede observarse su experiencia con ese sujeto cuyo significado deconstruye para conocer una nueva interacción amorosa-erótica femenina.

Y así flotas leve en mi cabecera

mientras duermo mirando tu cabeza

fría, tu densa cabellera azul y brillante

descolgando su peso con soltura

en medio de la noche...

Nos vislumbra la suavidad amorosa en esta figura monstruosa. Y nuevamente, estamos ante dos vías, una en que hay un sujeto lírico que goza a partir de ese momento onírico o bien dos corporeidades que se deleitan juntas

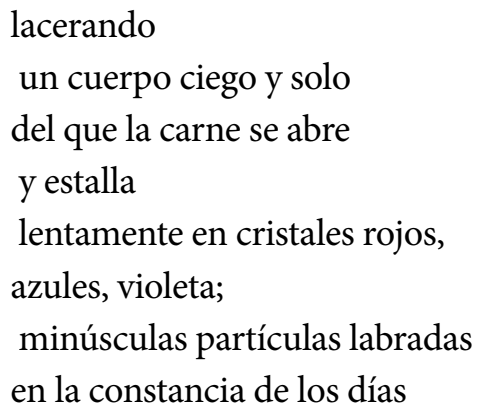

Ver a estos dos símbolos femeninos, Medusa y Atenea, que han representado el mal y el bien, en el ámbito de la heterosexualidad, fusionarse por unos instantes a partir del deseo y el erotismo que puede surgir entre ellas, nos lleva a imaginar durante unos instantes otro tipo de relación y de práctica sexual que ambas legitiman. Ahora bien, mezclar el rojo con el azul y convertirlo en violeta nos remite al color representativo lésbico, sobre todo después de la década del ochenta. De una manera muy velada pues no hay nada explícito en el verso, pero sí a partir de lo anteriormente expuesto, la pareja erótica de Atenea y Medusa no pondera rasgos de masculinidad o feminidad que les podrían ser atribuidos.

De esta manera Medusa vuelve a ser sexuada, erótica, como antes de lo ocurrido en el templo, Atenea traspasa la puerta que decidió tener cerrada y descubre su sexualidad con una mujer. Hay un contraste con su proceder previo y el acto ocurrido entre estos dos sujetos emblemáticos de feminidad aceptada y reprobable. Ellas encuentran el placer matizado de sensaciones diversas, sin embargo, esto no puede mantenerse. Siguiendo el poema, Atenea regresa a lo establecido moralmente:

Como animal agobiado de muerte

y vida, he de resistir en sueños

el frío del amor.

Guardo para ti una virginidad

viuda; 
Es evidente que se supieron sujetos ejerciendo su deseo. Estuvieron inmersas en ese destello que salpicaba y coloreaba el ambiente, pese a ello, ambas retornan a la resistencia y control de los sentimientos y placeres, Atenea se ubica de nueva cuenta como virgen y ahora viuda, pues su amante está muerta. Y así, concluye diciéndole:

si lames mi piel de principio a fin,

me clarificas, si muerdes mis venas

palidecen;

pues has vuelto la cabeza a mirarme

y ya soy de piedra

Un nuevo pacto se ha firmado entre la Cabeza de Medusa y Atenea: mantendrán un vínculo relacionado con el cuidado y decisión sobre la permanente virginidad de Atenea y la Cabeza de Medusa como celadora fiel y guardiana perpetua que impedirán el deseo y el placer. La complicidad compartida de haber transitado por sus deseos se aposta en esa petrificación, la inmovilidad de ambas las separa, pero al mismo tiempo las une.

\section{Conclusión}

A través de los poemas analizados de Nancy Cárdenas y Violeta Barrientos que apuntan a la sexualidad problematizada en el acto erótico-afectivo entre dos sujetos líricos femeninos, podemos develar esas prácticas sexuales que no habían sido nombradas o descritas desde el canon poético. En este sentido, sea desde el coloquialismo o mediante figuras retóricas que guardan cierta estética, el contenido de los versos que conforman los poemas de Cárdenas y de Barrientos se desmarcan de la manera en que ha sido construido el sujeto lírico femenino. Las estrategias para abordar el tema y mostrar a esos sujetos contestatarios fueron distintas: mientras en el poema Hoy (Cárdenas, 1994: 59) el referente es una importante literata francesa que causó controversia en el siglo pasado por acciones de su vida y su producción novelística, el poema La cabeza de Medusa (Barrientos, 2013: 17-18) deconstruye uno de los personajes míticos femeninos estigmatizado como un ser cruel y destinado a la muerte. Así pues, ambas han evidenciado el intersticio para poetizar de otra manera la feminidad, dar cabida a la corporeidad en la que está implicada la sexualidad y evidentemente alejarse de esa marca de género a través de la cual se conforman hombres y mujeres.

Al nombrarse esta interacción realizada entre dos sujetos líricos femeninos, cerrar la brecha intergeneracional, explicitar que en la vejez la sexualidad forma parte de la subjetividad femenina, es que entonces se convierte en un acto político lo que se constriñó dentro de la intimidad explicada bajo el argumento que legitimó que la feminidad estaba en contraposición de la masculinidad y que las características principales estaban relacionadas a la mesura, la obediencia y el ser para los otros. Por lo tanto, presentar el rechazo social y los caminos para confrontarlo me lleva a confirmar que "la experiencia es un proceso mediante el cual se construye la subjetividad de los seres sociales [...] El proceso es continuo y 
su final inalcanzable o diariamente nuevo" (De Lauretis, 1992: 253). Esto quiere decir que la subjetividad femenina no es estática y tampoco inherente a la naturalización de las prácticas sexuales, pues al haberse genitalizado la sexualidad poco se había hablado de las experiencias de las mujeres. De aquí que desde las últimas décadas del siglo pasado se haya pugnado por no generalizar a las lesbianas o sus prácticas sexuales, ya que como dijera en los noventa De Lauretis:

\begin{abstract}
Algunas mujeres siempre han sido lesbianas. Otras, como yo, han "devenido" lesbianas. Tanto construcción sociocultural como efecto de las primeras experiencias de la infancia, la identidad sexual no es ni innata ni simplemente adquirida, sino dinámicamente (re)estructurada por formas de fantasía privadas y públicas, conscientes e inconscientes, que están culturalmente a disposición y son históricamente específicas (De Lauretis, 1995: 43).
\end{abstract}

No obstante, es inexorable la imposibilidad social de aceptar que dos mujeres puedan sostener una relación erótico-amorosa-afectiva entre sí. Este discurso continúa vinculado al reglamento del género, a la idea de procreación y por supuesto al imaginario cotidiano que recrea un panóptico que el propio sujeto tiene que esforzarse para no seguir en él. Si bien el feminismo en sus inicios planteó el cuerpo como un lugar político, como un espacio de lucha, también es necesario reconocer que no todas las consignas coreadas en las marchas alcanzaron el cambio esperado en la sociedad, una de ellas fue: "No hay libertad política si no hay libertad sexual". Es necesario no perder de vista que el análisis de estos dos poemas ha hecho visible las conexiones de algunas lesbianas quienes se dieron a la tarea de discutir en el marco del feminismo y la necesidad de visualizar las prácticas sexuales, así como también evidenciar que el sujeto es sexuado y no estático a lo largo de su vida, lo que ha derivado en diversos saberes y aristas por explorar hasta la actualidad, entre ellos los vínculos erótico-afectivos a través de la historia y de las generaciones. Para tal efecto se realizaron encuentros lésbicos feministas que iniciaron en la década del ochenta. En este mismo sentido menciono los aportes de teóricas como Judith Butler y Teresa De Lauretis, quienes se han propuesto no replicar la heteronormatividad en sus vidas y cuyo análisis y propuestas se dirigen a lograr la inclusión de los sujetos. Justamente observamos la contribución del vínculo literario, en este caso, poético y un marco feminista al generar un lente complejo y colorido, cuyas tonalidades destacan versiones de la historia humana que en muchas ocasiones y momentos se silencian por la heteronormatividad.

Así pues, Violeta Barrientos se concentra en presentar la corporeidad como un lugar de transformación y de encuentro en el que nos permite ver la autorreflexión de un sujeto que se cuestiona y observa sus posibilidades. El temor existe al reconocerse a sí misma y por ello busca las estrategias para vivir en un mundo que no acepta cotidianamente otras formas de vida, de relación de pareja, entre otras más.

A través de los poemas presentados de Nancy Cárdenas y Violeta Barrientos observamos el entreverado en que se inserta la idea de ser mujer y con ella la respuesta erótica. Contrasta entre un poema y otro el doloroso camino por el cual deben atravesar las mujeres que han sido catalogadas como seres abyectos e indeseables. Hoy (Cárdenas, 1994: 59) nos deja la sensación de que hay un mañana para conseguirlo y que será ese futuro que podrá presentar otras opciones de vida; por otro lado, nos recrea a un sujeto lírico que se deconstruye e inserta en un espacio en el que el miedo y la categorización son persistentes, como ocurre en la estigmatización y castigo en La cabeza de Medusa (Barrientos, 2013: 17-18). A pesar de ello, en ésta hay un pacto, un momento en que las prácticas sexuales, las relaciones erótico-afectivas 
entre mujeres son cómplices para gestar un mundo en que sí puedan transitar.

Por mucho tiempo las relaciones han sido silenciadas en distintos espacios y momentos históricos, esto no ha impedido que la experiencia ocurrida no fuese contada por estas silentes bulliciosas cuya obra ha permanecido logrando el objetivo de dar cuenta de esa experiencia en ese nuevo sujeto lírico (¿femenino?). Aunque nos hayan hecho creer que hay un gran silencio, lo cierto es que las voces han estado y siguen alzándose, basta detenerse ante el bullicio derivado de la voz del silencio.

\section{Referencias}

Aguirre, Mercedes. 1998. Las Gorgonas en el mediterráneo occidental. Revista de Arqueología, 19 (207): 22-31.

Arber, Sara y Ginn Jay (Coords.). 1996. Relación entre género y envejecimiento. Enfoque sociológico. Serie Mujeres. Madrid: Narcea Ediciones.

Barrientos, Violeta. 2013. El innombrable cuerpo del deseo. Perú: Intermezzo Tropical.

Buttler, Judith. 2002. Cuerpos que importan. Sobre los límites materiales y discursivos del "sexo". Buenos Aires: Paidós.

2009. Performatividad, precariedad y políticas sexuales. AIBR. Revista de Antropología Iberoamericana, 3 (4): 321-336.

Cárdenas, Nancy. 1994. Cuaderno de amor y desamor, (1968-1993). México: Hoja Casa Editorial.

De Beauvoir, Simone. 1962. El segundo sexo. Argentina: Siglo Veinte.

De Lauretis, Teresa. 1992. Alicia ya no. Madrid: Ediciones Cátedra.

(11): 34-45.

1995. La práctica del amor: deseo perverso y sexualidad lesbiana. Debate Feminista. 6

Fuentes, Adriana. 2015. Decidir sobre el propio cuerpo. Una historia reciente del Movimiento Lésbico en México. México: La Cifra Editorial, UAM-X.

García, Maricarmen. 2003. Gabrielle Colette y la novela feminista. Graffylia: Revista de la facultad de Filosofía y Letras. 1 (1): 71-78. México: BUAP.

Muñiz, Elsa. 2004. Historia y género. Hacia la construcción de una historia cultural del género. En Voces disidentes. Debates contemporáneos en los estudios de género en México, coordinado por Sara Pérez, Gil Romo y Patricia Ravelo. México: CIESAS, 31-55.

Radclyffe, Hall. 1965. El pozo de la soledad. México: Diana.

Sánchez, Diana. 2000. Gerontología social. Argentina: Espacio Editorial.

Scott, Joan. 1999. La experiencia como prueba. En Feminismos Literarios, compilado por Neus Carbonell y Meri Torras. Madrid: Arco/Libros, 77-112.

Thurman, Judith. 2006. Los secretos de la carne: Vida de Colette. España: Siruela.

Valdiosera, Ramón. 1973. El lesbianismo en México. México: Editores Asociados.

Vázquez, Ana. 2013. La Gorgona Medusa ¿Un posible mito tartésico? Huelva Arqueológica, 20: 195-214. Walkowitz, Judith. 1993. Sexualidades peligrosas. En Historia de las mujeres en occidente, vol. 5. México: Taurus, 389-426. 